\title{
Hadley Circulation Response to Orbital Precession. Part I: Aquaplanets
}

\author{
TIMOTHY M. MERLIS \\ Princeton University, and Geophysical Fluid Dynamics Laboratory, Princeton, New Jersey \\ TAPIO SCHNEIDER AND SIMONA BORDONI \\ California Institute of Technology, Pasadena, California \\ IAN EISENMAN \\ Scripps Institution of Oceanography, University of California, San Diego, La Jolla, California
}

(Manuscript received 6 December 2011, in final form 24 July 2012)

\begin{abstract}
The response of the monsoonal and annual-mean Hadley circulation to orbital precession is examined in an idealized atmospheric general circulation model with an aquaplanet slab-ocean lower boundary. Contrary to expectations, the simulated monsoonal Hadley circulation is weaker when perihelion occurs at the summer solstice than when aphelion occurs at the summer solstice. The angular momentum balance and energy balance are examined to understand the mechanisms that produce this result. That the summer with stronger insolation has a weaker circulation is the result of an increase in the atmosphere's energetic stratification, the gross moist stability, which increases more than the amount required to balance the change in atmospheric energy flux divergence necessitated by the change in top-of-atmosphere net radiation. The solstice-season changes result in annual-mean Hadley circulation changes (e.g., changes in circulation strength).
\end{abstract}

\section{Introduction}

The general circulation of the atmosphere plays a key role in determining the surface climate of Earth. In low latitudes, the Hadley circulation determines the structure of convergence zones, which in turn shape the precipitation distribution. Therefore, changes in the atmospheric circulation must have contributed to climate changes in Earth's history. The changes associated with Earth's orbital parameters are of particular interest because they cause variations in top-of-atmosphere insolation and a host of proxies show variations on the relevant time scales. Here, we use an idealized atmospheric general circulation model (GCM) to examine the response of the Hadley circulation to the insolation changes associated with orbital precession that occur on $\sim 20$-kyr time scales. Precession-forced changes to the insolation seasonal cycle are hemispherically antisymmetric (e.g., when the

Corresponding author address: Timothy M. Merlis, Princeton University, and Geophysical Fluid Dynamics Laboratory, Jadwin Hall, Princeton, NJ 08544.

E-mail: tmerlis@princeton.edu
Northern Hemisphere summer is bright, the Southern Hemisphere summer is dim), but orbital precession does not change the annual-mean insolation at a given latitude (e.g., a bright Northern Hemisphere summer is offset by a dim Northern Hemisphere winter).

The Hadley circulation is constrained by the atmospheric angular momentum balance, as reviewed by Schneider (2006). Briefly, the equinox and summer Hadley cells in Earth's atmosphere are in a dynamical regime in which the divergence of angular momentum by the large-scale extratropical eddies is important in determining the strength of the circulation (Schneider et al. 2010). In contrast, the cross-equatorial winter or monsoonal Hadley cells are in a different regime-one in which the eddy momentum flux divergence is weak and the circulation is near the angular momentum-conserving limit and responds more directly to energetic perturbations (Held and Hou 1980; Held 2001a; Schneider and Bordoni 2008; Bordoni and Schneider 2008).

The extension of the angular momentum-conserving Hadley cell theory to off-equatorial thermal forcing (Lindzen and Hou 1988) suggests substantial strengthening of the circulation in response to larger thermal forcing 
gradients and increased displacements of the thermal forcing maximum away from the equator, provided the gross stability (the parameter relating energy and mass fluxes) is fixed. We show that in simulations in which this stability is free to change the strength of the atmospheric mass transport can decrease in response to increases in insolation and its meridional gradient. Energy balance considerations constrain the product of the circulation strength and the gross moist stability (Held 2001a); changes in either factor can counteract each other in achieving energy balance.

Energetic constraints may be used to understand how tropical atmospheric circulations near the angular momentum-conserving limit respond to radiative perturbations. Studying this parameter regime is of interest to both the cross-equatorial Hadley circulation and regional circulations such as the Asian monsoon. The simulations presented here have zonally symmetric surface boundary conditions but are in the dynamical regime that is relevant to the Asian monsoon, as in Bordoni and Schneider (2008).

The conventional picture of monsoons as land-seabreeze circulations driven by warmer surface temperatures over land (e.g., Webster and Fasullo 2003) suggests that stronger summer insolation leads to stronger monsoonal circulations (Ruddiman 2008, chapter 8). While this picture of monsoons has been called into question (Bordoni and Schneider 2008), an early GCM simulation with fixed sea surface temperature and interactive land surface temperature met the expectation of a stronger circulation in the Asian monsoon region when perihelion occurs in Northern Hemisphere summer (Kutzbach 1981). GCM experiments with energetically consistent surface boundary conditions over land and ocean have found both strengthening and weakening of the crossequatorial Hadley circulation in Northern Hemisphere summer in response to orbital precession (Khon et al. 2010; Clement et al. 2004). Brayshaw et al. (2010) found a stronger cross-equatorial Hadley circulation in Northern Hemisphere winter in simulations of the midHolocene, which had reduced insolation in that season compared to the present. Last, the simulations presented in Ashkenazy et al. (2010) have little change in Hadley circulation strength but a shift in seasonality in response to changes in orbital parameters.

The goal of this work is to isolate the key dynamical mechanisms that control the strength of monsoonal Hadley circulations in idealized atmospheric GCM simulations that are amenable to conceptual progress. The changes in the solstice-season Hadley circulations lead to annual-mean Hadley circulation changes. In this paper, we examine GCM simulations with an aquaplanet, slab-ocean lower boundary condition. In a companion paper, we examine GCM simulations with an idealized representation of land surface processes with a zonally symmetric subtropical continent geometry (Merlis et al. 2013a, hereafter Part II). This is a key step toward understanding comprehensive GCM simulations, such as those of the mid-Holocene performed as part of the $\mathrm{Pa}$ leoclimate Modeling Intercomparison Project (Braconnot et al. 2007), and building confidence in the fidelity of their results.

\section{Idealized GCM}

We use an idealized moist atmospheric GCM based on the Geophysical Fluid Dynamics Laboratory (GFDL) spectral dynamical core and the radiation scheme of the GFDL AM2 comprehensive atmospheric GCM (Anderson et al. 2004). We briefly describe the GCM's representations of physical processes, which follows the work of Frierson (2007), O'Gorman and Schneider (2008), and Bordoni and Schneider (2008) except for the radiation scheme.

The GCM's active hydrological cycle solely models the vapor-liquid phase transition, with a constant latent heat of vaporization. Precipitation occurs when resolved motion leads to supersaturation and in a simplified BettsMiller convection scheme that relaxes convectively unstable columns to a moist pseudoadiabat with constant $(70 \%)$ relative humidity over a fixed time scale (Frierson 2007). When precipitation occurs, it is assumed to immediately fall to the surface, so there is no liquid water in the atmosphere.

The spectral dynamical core integrates the primitive equations with $\mathrm{T} 42$ horizontal resolution and 30 vertical levels. In addition to $\nabla^{8}$ hyperviscosity throughout the atmosphere, there is $\nabla^{2}$ viscosity with coefficient $4.0 \times$ $10^{6} \mathrm{~m} \mathrm{~s}^{-2}$ that acts on the zonal and meridional winds in the highest model level. The GCM's leapfrog time step is $900 \mathrm{~s}$. Averages are taken over the last $20 \mathrm{yr}$ following a spinup period of $10 \mathrm{yr}$ from an isothermal, resting initial condition or from a simulation with similar parameters.

The ocean energy flux divergence plays an important role in determining aspects of the tropical circulation (Held 2001b; Herweijer et al. 2005; Levine and Schneider 2011). Therefore, we prescribe a zonally symmetric ocean energy flux divergence (" $Q$ flux"; see Part II for details) that is time independent and similar to the zonal mean of estimates based on reanalyses (Bordoni 2007; Bordoni and Schneider 2008). The surface heat capacity is that of $5 \mathrm{~m}$ of water, and the surface albedo is 0.1 uniformly.

We focus on simulations with low surface thermal inertia, as this limit features seasonally large Rossby numbers and permits convergence zones to migrate poleward to 
latitudes similar to the Asian monsoon (Bordoni and Schneider 2008). In addition, the low thermal inertia reduces the magnitude of energy storage, so aspects of the climate are close to being in equilibrium with the instantaneous insolation. It is also useful to have somewhat exaggerated changes to clearly isolate them. As a thermal inertia this small is not relevant for oceancovered regions, we compare to simulations with larger surface thermal inertia (that of $20 \mathrm{~m}$ of water) throughout the text. We have also performed simulations with different convection scheme parameters (postconvective relative humidity of $90 \%$ ) and higher horizontal resolution (T85 truncation). The response to orbital precession is similar to the simulations presented here.

The radiative transfer is the most significant departure from previous work and is described next.

\section{a. Radiative transfer}

Previous work with similar idealized GCMs has employed gray radiation with prescribed, latitudedependent optical depths. This approach has limitations; for example, in the case of tidally locked exoplanets, this is inappropriate as it ignores important water vapor variations in longitude (Merlis and Schneider 2010). Here, our concern is that details of the seasonal cycle can be influenced by the water vapor feedback, so we employ the comprehensive radiation scheme described in Anderson et al. (2004).

Adding a comprehensive treatment of radiative transfer necessitates including clouds in some fashion. This is because the meridional structure of cloud properties and the associated radiative forcing determines, in part, the meridional temperature gradient. In the extratropics, clouds have a net cooling effect, while in low latitudes there is little net warming or cooling (e.g., Hartmann 1994). Therefore, without the cloud radiative forcing, the equator-to-pole temperature difference would be reduced.

The approach taken here is to prescribe timeindependent low clouds and to neglect the ice-phase clouds of the upper troposphere. ${ }^{1}$ The model hydrological cycle does not simulate liquid water, so the prescribed cloud liquid water field only enters the model formulation in the radiative transfer calculation. We neglect possibly important but uncertain cloud changes to focus on aspects of the climate response that are likely to be robust across different GCM formulations.

\footnotetext{
${ }^{1}$ Low clouds in polar regions where the air temperature is below the freezing point of water are still assumed to be in the liquid water phase.
}

The vertical structure of the cloud liquid water specific humidity is given by a half-sine function over the lowest quarter of the atmosphere,

$$
\ell(\sigma)= \begin{cases}2 \pi \ell_{0} \sin (-4 \pi \sigma) & \text { if } \sigma>0.75 \\ 0 & \text { otherwise }\end{cases}
$$

where $\sigma=p / p_{s}$ is the GCM's vertical coordinate. The vertical structure is inspired by observations (cf. Fig. 4a of $\mathrm{Li}$ et al. 2008) but is highly idealized. The normalization factor $2 \pi$ is included so that the mass-weighted vertical integral of cloud water over the atmosphere (proportional to the liquid water path) takes the value of $\ell_{0}$. Satellite observations suggest cloud water varies from $\sim 0.01 \mathrm{~kg} \mathrm{~m}^{-2}$ in low latitudes to $\sim 0.1 \mathrm{~kg} \mathrm{~m}^{-2}$ in high latitudes ( $\mathrm{Li}$ et al. 2008). We use $\ell_{0}=0.1 \times 10^{-5}$, which corresponds to $0.01 \mathrm{~kg} \mathrm{~m}^{-2}$ at all latitudes. This is a smaller value in high latitudes than observed; it is chosen to keep the global-mean temperature like Earth, as neglecting clouds higher in the atmosphere can raise the emission temperature of the planet.

The cloud fraction $f$ is vertically uniform in the atmosphere, ${ }^{2}$ but it varies meridionally as

$$
f(\phi)=f_{\mathrm{eq}}+\left(f_{p}-f_{\mathrm{eq}}\right) \sin ^{2} \phi .
$$

We use $f_{\text {eq }}=0.02$ and $f_{p}=0.4$.

The solar constant is $1365 \mathrm{~W} \mathrm{~m}^{-2}$, and there is no diurnal cycle. The only greenhouse gas is $\mathrm{CO}_{2}$ with a concentration of $300 \mathrm{ppm}$ in the simulations. No ozone, aerosol, or other greenhouse gases are included in the radiative transfer calculation.

\section{b. Insolation changes}

Earth's orbital eccentricity-defined as the difference of the semimajor and semiminor axes over their sumleads to a seasonal cycle associated with the changing Earth-Sun distance $r$; this seasonal cycle is weaker than that associated with obliquity. The perihelion precesses over a $\sim 20$-kyr period, so the seasonal cycle in top-ofatmosphere insolation varies on these time scales. But, the annual-mean insolation at a given latitude does not depend on the phase of perihelion. This is a consequence of canceling factors of the square of the EarthSun distance $r^{2}$ in the conservation of angular momentum (Earth moves faster through the orbit when it is closer to the sun) and the radiative flux reaching Earth, which depends inversely on $r^{2}$.

\footnotetext{
${ }^{2}$ Cloud fraction has no effect on the radiative transfer where cloud liquid water and ice water is zero.
} 

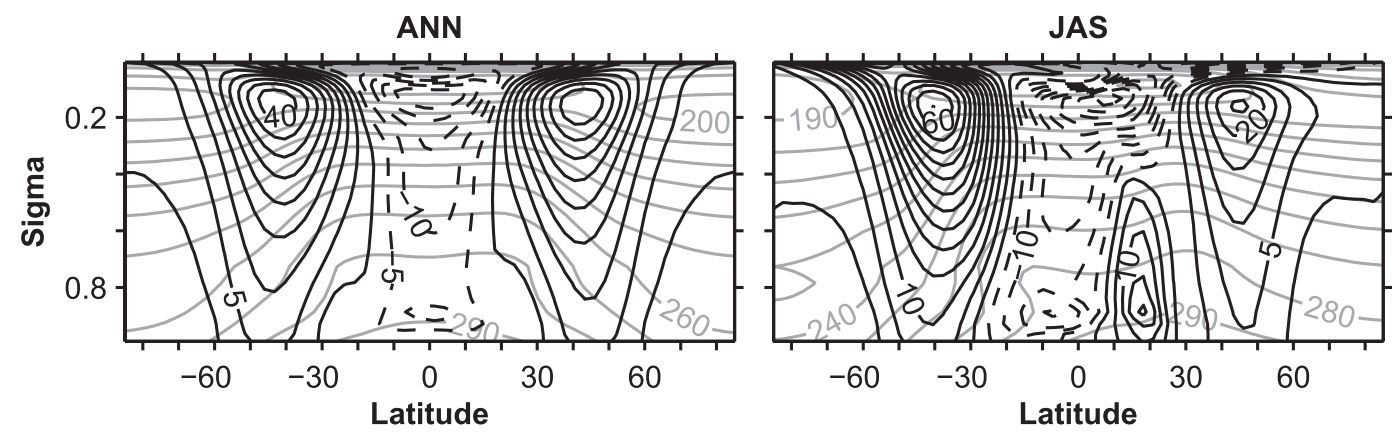

FIG. 1. Zonal-mean zonal wind (black) and temperature (gray) for (left) the annual mean and (right) the JulySeptember mean of the December perihelion simulation. The contour interval is $5 \mathrm{~m} \mathrm{~s}^{-1}$ for the zonal wind and $10 \mathrm{~K}$ for the temperature.

Note that climate statistics that are linear in insolation will not change in the annual mean when the phase of the perihelion is varied since the annual-mean insolation does not change. If a climate statistic has annualmean changes when the perihelion is varied, a nonlinear process is operating that rectifies the insolation changes.

We vary the orbital configuration using a 360-day year. The reference orbital parameters we use are a near-contemporary obliquity of $23^{\circ}$; a relatively large eccentricity of 0.05 ; and perihelion occurring at Southern Hemisphere summer solstice, which is close to the contemporary value. We refer to this as "December perihelion" for brevity. The annual-mean and Northern Hemisphere summer-mean zonal wind and temperature are shown in Fig. 1. The perturbation experiment has perihelion occurring at Northern Hemisphere summer solstice, referred to as "June perihelion."

The change in downward top-of-atmosphere shortwave radiation between the two perihelion configurations is shown in Fig. 2. When the perihelion is changed to Northern Hemisphere summer solstice (June perihelion), the top-of-atmosphere insolation increases in the Northern Hemisphere summer and decreases in the Southern Hemisphere summer (Fig. 2). With eccentricity of 0.05 , the instantaneous insolation changes are $\sim 50 \mathrm{~W} \mathrm{~m}^{-2}$ in the tropics. At each latitude, the annualmean insolation does not change (Fig. 2, right). We use a large eccentricity so that the precession-forced insolation changes are large; however, the climate changes are similar, albeit smaller in magnitude, in simulations with smaller eccentricity. For example, the precessionforced circulation anomalies (bottom panels of Figs. 4, 5) are approximately linear in the eccentricity, so the magnitude of the anomalies is about a factor of 5 smaller in simulations with eccentricity of 0.01 .

Apart from the effect of limited time sampling, timemean asymmetries between the hemispheres in the GCM simulations are a consequence of rectification of the time-dependent asymmetry in insolation. In fact, one could compare the hemispheres (i.e., the degree of hemispheric asymmetry) to determine the effect of changing precession between the solstices, since the boundary conditions and forcing are otherwise hemispherically symmetric. We do not take that approach here to maintain continuity in the presentation of results, as the

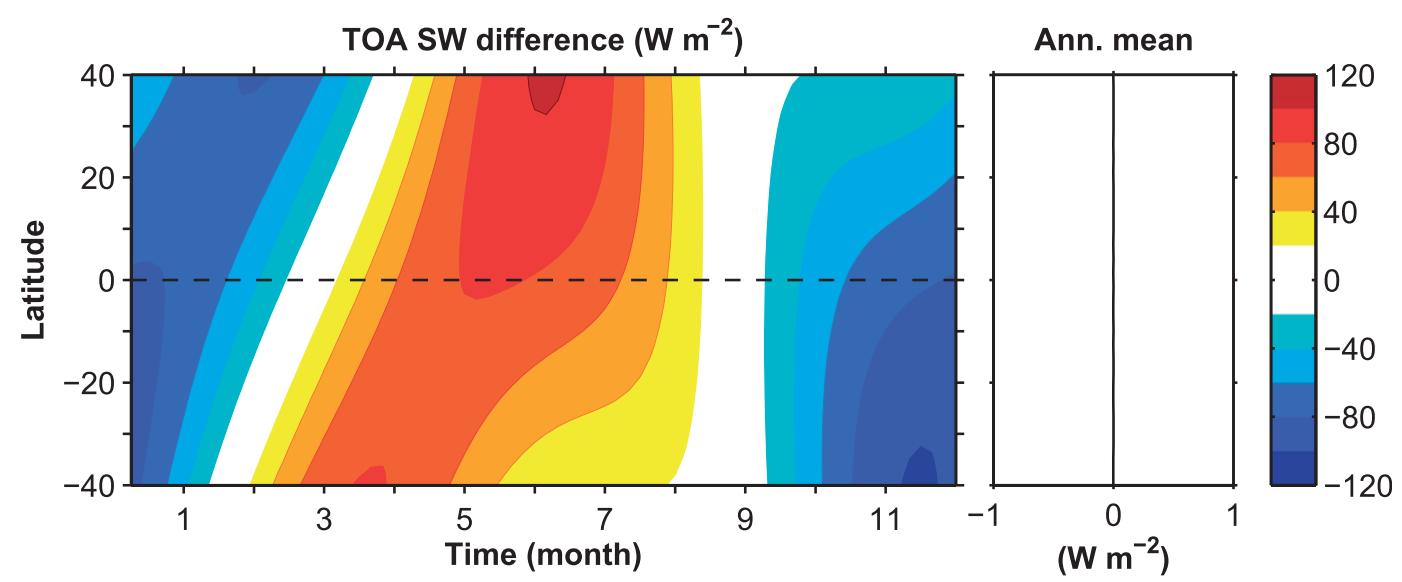

FIG. 2. (left) Seasonal cycle of the top-of-atmosphere insolation difference between perihelion in June and December with contour interval of $20 \mathrm{~W} \mathrm{~m}^{-2}$. (right) Annual-mean top-of-atmosphere insolation difference. 

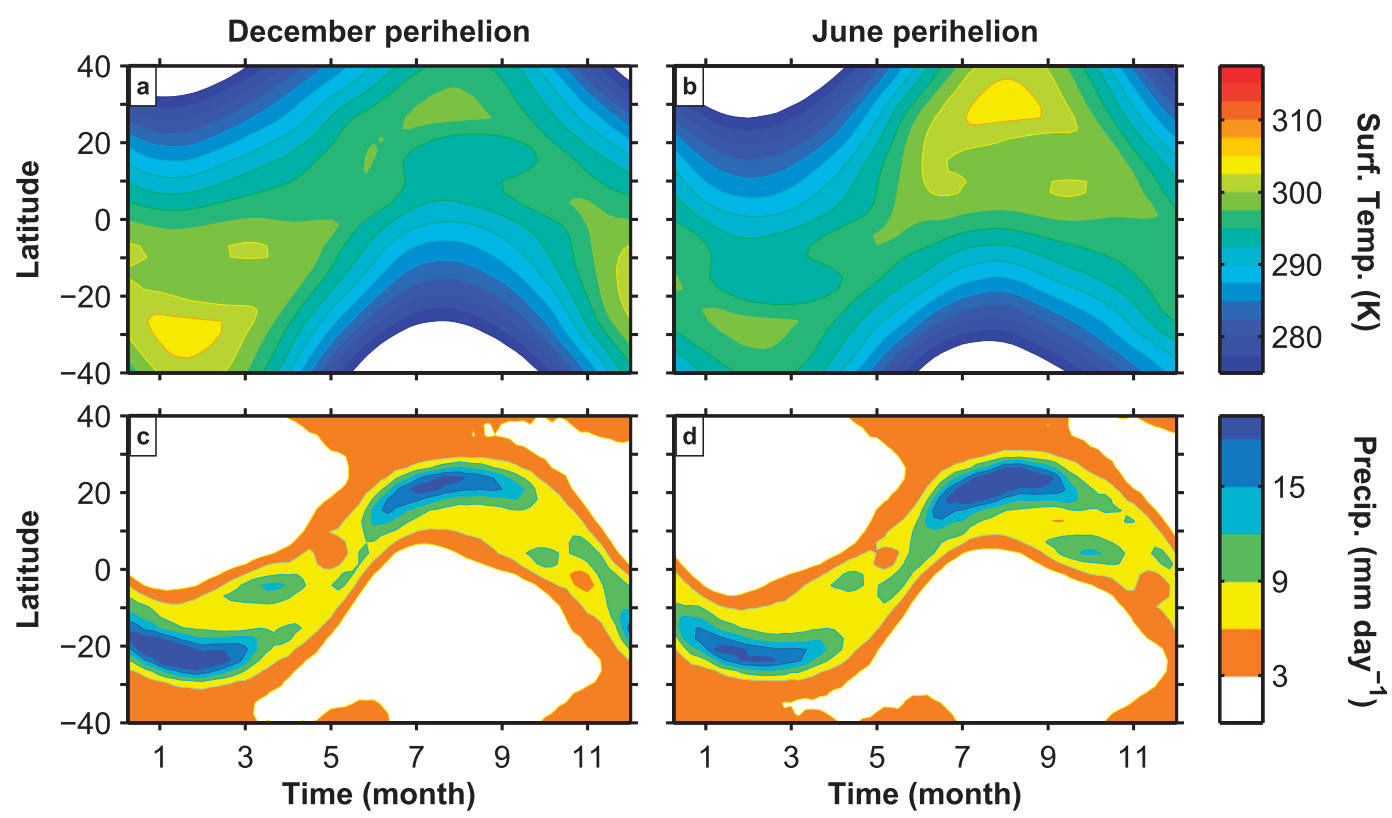

FIG. 3. (a),(b) Seasonal cycle of surface temperature and (c),(d) seasonal cycle of precipitation for simulations with (a),(c) perihelion in December and (b),(d) perihelion in June. The contour interval is $2.5 \mathrm{~K}$ for surface temperature and $3 \mathrm{~mm}$ day ${ }^{-1}$ for precipitation.

simulations in Part II have hemispherically asymmetric boundary conditions.

\section{Surface climate and Hadley circulation}

\section{a. Surface climate}

The seasonal cycle of surface temperature in low latitudes for the December perihelion simulation is shown in Fig. 3a. The maximum surface temperature $(\sim 300 \mathrm{~K})$ occurs in the bright Southern Hemisphere summer. The phase lag of the surface temperature maximum relative to the maximum insolation is $\sim 1$ month. The amplitude of the seasonal cycle increases from $\sim 5 \mathrm{~K}$ near the equator to $\sim 10 \mathrm{~K}$ at $30^{\circ}$. These surface temperature variations are exaggerated compared to the zonal mean on Earth as a result of the low surface thermal inertia.

Figure $3 c$ shows the seasonal cycle of precipitation in low latitudes for the December perihelion simulation. The latitude of maximum precipitation and the intertropical convergence zone move seasonally into the summer hemisphere. The region of large precipitation is $15^{\circ}-25^{\circ}$, as in the Asian monsoon region. The precipitation maximum rapidly crosses the equator because of the low thermal inertia of the surface [see Schneider and Bordoni (2008) and Bordoni and Schneider (2008) for analyses of the mechanisms that generate rapid transitions in convergence zones over the course of the seasonal cycle].

The surface temperature in the June perihelion simulation has changes relative to the December perihelion simulation that echo the insolation changes (Figs. 3a,b, 2) with a phase lag of $\sim 1$ month. So, as expected, the summer with more insolation is warmer than the summer with less insolation. The seasonal changes average to about $0.1 \mathrm{~K}$ in the annual mean.

The precipitation changes are phased similarly to those of the insolation and surface temperature: more precipitation occurs in the summer with perihelion (Figs. 3c,d). The annual-mean precipitation is $1 \mathrm{~mm} \mathrm{day}^{-1}(\sim 15 \%)$ larger in the hemisphere with perihelion coinciding with the summer solstice. The mechanisms that give rise to the annual-mean precipitation changes are examined in Merlis et al. (2013b).

\section{b. Hadley circulation}

Figure 4 (top) shows the annual-mean streamfunction, which is weak $\left(\sim 50 \times 10^{9} \mathrm{~kg} \mathrm{~s}^{-1}\right)$ in these simulations compared to Earth's $\left(\sim 100 \times 10^{9} \mathrm{~kg} \mathrm{~s}^{-1}\right)$. This is because the annual-mean circulation is dominated by partially compensating and strong summer-season and winter-season solstitial circulations, which result from using a surface heat capacity that is low compared to the zonal mean of Earth (section 5). This is a counterexample to the notion that strong solstitial circulations lead to stronger annual-mean circulations (Lindzen and $\mathrm{Hou}$ 1988). Simulations with a surface heat capacity of $20 \mathrm{~m}$ of water have streamfunction maxima $\left(\sim 80 \times 10^{9} \mathrm{~kg} \mathrm{~s}^{-1}\right)$ that are more similar to Earth's. The change associated with moving perihelion from December to June is a 

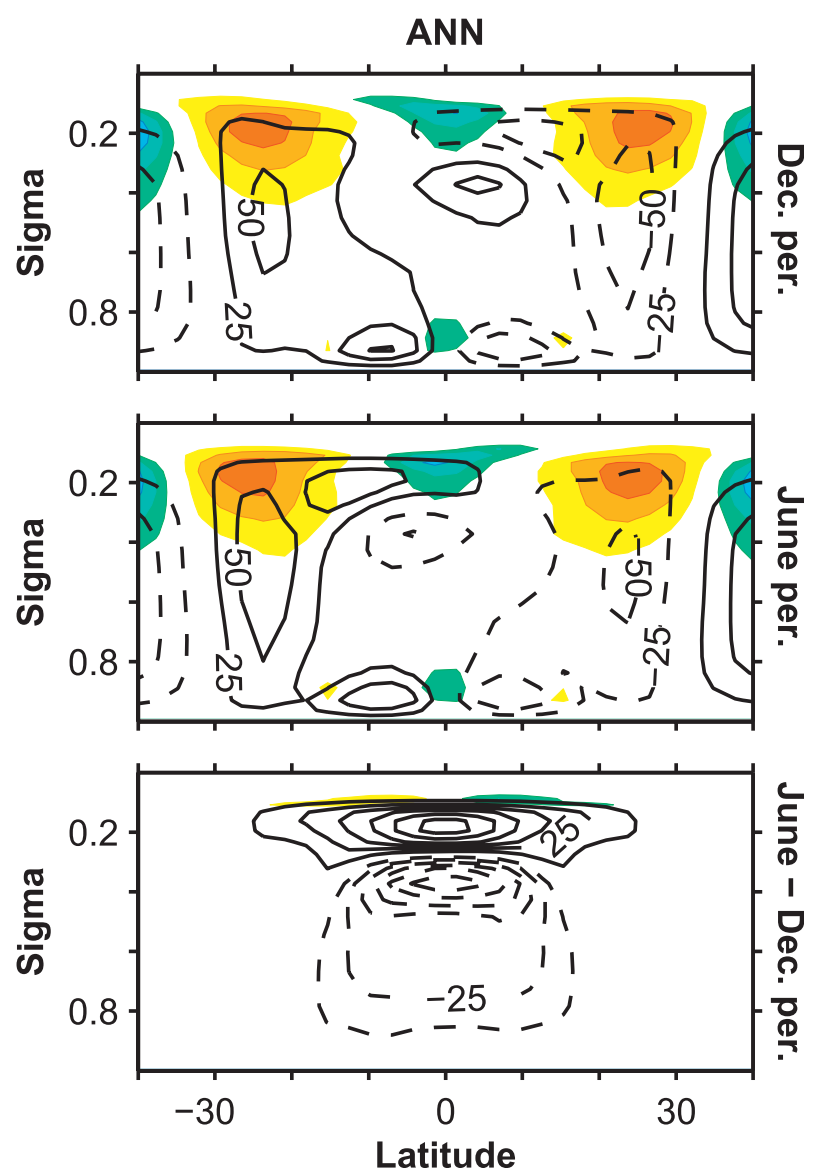

FIG. 4. Annual-mean mass flux streamfunction (contours) with contour interval $25 \times 10^{9} \mathrm{~kg} \mathrm{~s}^{-1}$ and eddy angular momentum flux divergence (colors) with contour interval $1.2 \times 10^{-5} \mathrm{~m} \mathrm{~s}^{-2}$ for simulation with (top) December perihelion and (middle) June perihelion. (bottom) Difference in annual-mean mass flux streamfunction (contours) with contour interval $12.5 \times 10^{9} \mathrm{~kg} \mathrm{~s}^{-1}$ and eddy angular momentum flux divergence (colors) with contour interval $0.6 \times 10^{-5} \mathrm{~m} \mathrm{~s}^{-2}$ between simulations with perihelion in June and December (June - December).

strengthening of the annual-mean Northern Hemisphere cell and a weakening of the annual-mean Southern Hemisphere cell below the upper troposphere that is centered on the equator (Fig. 4, bottom).

The eddy angular momentum flux divergence is maximum in the upper troposphere near $20^{\circ}$ (color contours in Fig. 4). On the equator, there is a region of eddy momentum flux convergence, which is related to the convergence that appears seasonally in the upper branch of the cross-equatorial Hadley circulation (Fig. 5). The changes in eddy momentum fluxes when perihelion is varied are consistent with the strengthening Southern Hemisphere (strengthened eddy momentum flux divergence) cell and weakening Northern Hemisphere (weakened eddy momentum flux divergence) cell in the upper troposphere though, as discussed in section 6 , these changes do not appear to be quantitatively important in determining the magnitude of changes in the annualmean Hadley cell mass fluxes.

We closely examine the July-September ${ }^{3}$ (JAS) timemean circulation, as this is the canonical Northern Hemisphere summer monsoon season. The Eulerianmean streamfunction averaged over JAS is shown in Fig. 5. The cross-equatorial Hadley circulation is strong (maximum $\sim 450 \times 10^{9} \mathrm{~kg} \mathrm{~s}^{-1}$ ) compared to Earth observations (maximum value $\sim 200 \times 10^{9} \mathrm{~kg} \mathrm{~s}^{-1}$ in the zonal mean or $\sim 350 \times 10^{9} \mathrm{~kg} \mathrm{~s}^{-1}$ for a mean over the longitudes of the Asian monsoon; Schneider et al. 2010; Bordoni and Schneider 2008). The magnitude of the JAS Hadley circulation is closer to observed zonal means in simulations with 20 -m slab depth (maximum value $\sim 200 \times$ $10^{9} \mathrm{~kg} \mathrm{~s}^{-1}$ ); this is associated with surface energy storage, rather than the atmospheric energy flux divergence, balancing more of the seasonal top-of-atmosphere insolation in the 20-m slab depth simulations than in the 5 -m slab depth simulations (the top-of-atmosphere energy balance is described in section 5). There is eddy momentum flux divergence in the subtropics of the winter and summer hemispheres with larger magnitude in the winter hemisphere as a result of the stronger eddy activity in winter (Fig. 5). Just north of the equator, there is eddy momentum flux convergence, which is likely the result of barotropic instability.

When the perihelion occurs in June, the Hadley circulation is shifted upward compared to the December perihelion simulation, as can be seen by the pattern of negative perturbation streamfunction values in the midtroposphere and positive perturbation streamfunction in the upper troposphere (Fig. 5, bottom). The streamfunction maximum is reduced to $\sim 400 \times 10^{9} \mathrm{~kg} \mathrm{~s}^{-1}$ when the perihelion occurs in June and the Northern Hemisphere summer is receiving more insolation (Fig. 5, middle). The changes in eddy momentum fluxes also have a vertical dipole pattern with larger magnitudes near the tropopause and reduced magnitudes below. However,

\footnotetext{
${ }^{3}$ The calendar is defined with respect to the Northern Hemisphere autumnal equinox; that is, the autumnal equinox occurs on 21 September for all orbital parameters. In all simulations, JAS is defined as Julian days 181-270 without shifts that would account, for example, for the changing day of the year of the Northern Hemisphere summer solstice, which shifts by about 10 days for these orbits (see Fig. 7). Similar results are obtained if these calendar effects are accounted for by averaging from the Northern Hemisphere summer solstice to the Northern Hemisphere autumnal equinox of each orbit (i.e., averages defined by the same angles in the orbital plane; cf. Joussaume and Braconnot 1997). Also, Fig. 7 shows that the difference between the streamfunction maxima in the simulations is similar in magnitude to the difference of the JAS time averages (Fig. 5).
} 

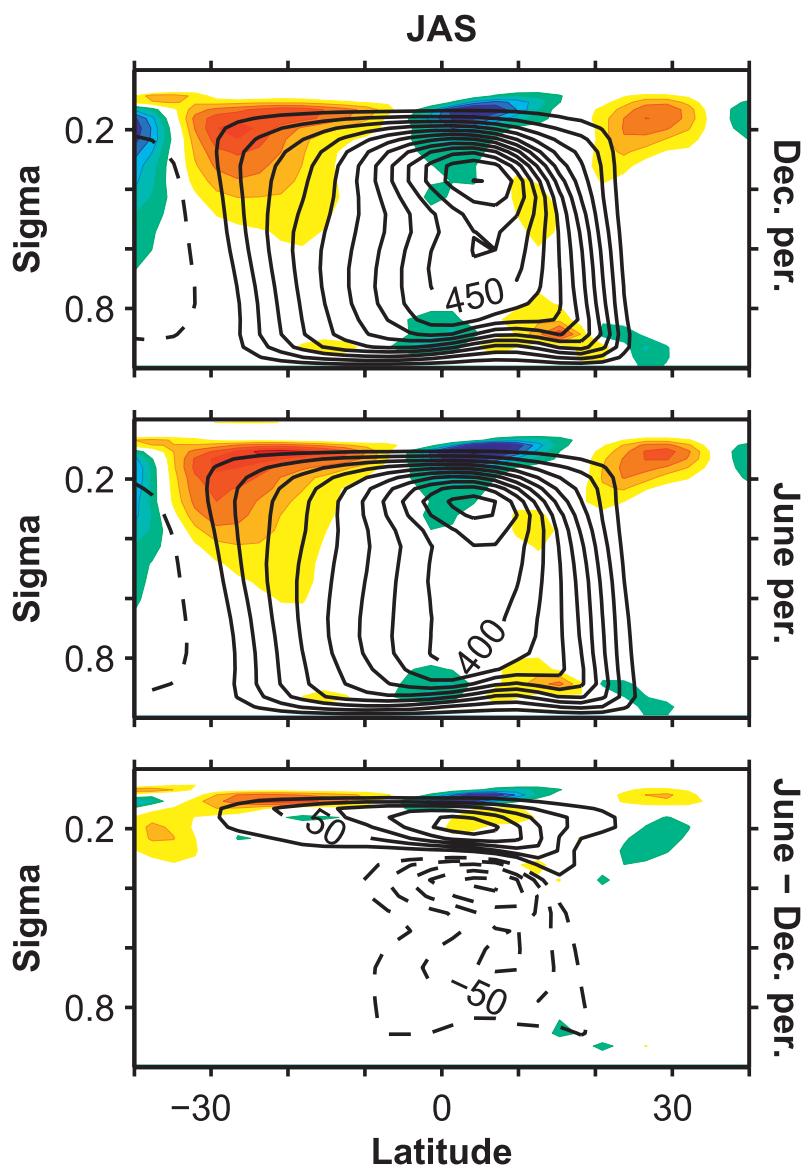

FIG. 5. JAS-mean mass flux streamfunction (contours) with contour interval $50 \times 10^{9} \mathrm{~kg} \mathrm{~s}^{-1}$ and eddy angular momentum flux divergence (colors) with contour interval $1.2 \times 10^{-5} \mathrm{~m} \mathrm{~s}^{-2}$ for simulation with (top) December perihelion and (middle) June perihelion. (bottom) Difference in JAS-mean mass flux streamfunction (contours) with contour interval $25 \times 10^{9} \mathrm{~kg} \mathrm{~s}^{-1}$ and eddy angular momentum flux divergence (colors) with contour interval $1.2 \times 10^{-5} \mathrm{~m} \mathrm{~s}^{-2}$ between simulations with perihelion in June and December (June - December)

as discussed in the next two sections, the changes in momentum fluxes are not central to the changing circulation strength. Note that the Hadley circulation is weaker in the June perihelion simulation than in the December perihelion simulation even though there is a stronger surface temperature gradient in the June perihelion simulation (Fig. 3).

Figure 6 shows the seasonal cycle of the midtropospheric zero-streamfunction contour, which is the boundary between the cross-equatorial Hadley cell and the summer Hadley cell. As a result of the low surface thermal inertia, the convergence zones are displaced into subtropical latitudes in summers (black lines in Fig. 6). This is more similar to the latitudes that the Asian monsoon reaches than the oceanic intertropical convergence zone. There is a phase shift when perihelion is

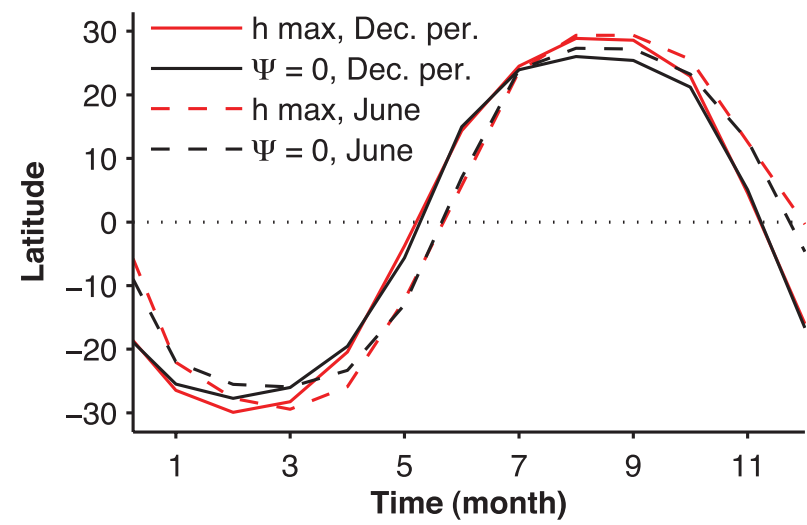

FIG. 6. Seasonal cycle of the latitude of the maximum nearsurface moist static energy $h$ (on the $\sigma=0.93$ model level; red lines) and the convergence zone between the cross-equatorial and summer Hadley cells (defined as the streamfunction zero on the $\sigma=0.67$ model level; black lines) for simulations with perihelion in December (solid lines) and June (dashed lines).

varied (cf. black solid and dashed lines in Fig. 6), but neither the fraction of the year spent in each hemisphere nor the poleward extent changes substantially.

The Hadley cell boundary is collocated with the maximum in near-surface moist static energy $h=c_{p} T+g z+$ $L q$ (red lines in Fig. 6), as suggested by Privé and Plumb (2007). This is discussed more in Part II.

\section{Angular momentum balance}

\section{a. Theory}

The steady angular momentum balance of the free troposphere (away from the near-surface region of friction) is ${ }^{4}$

$(f+\bar{\zeta}) \bar{v}-\bar{\omega} \frac{\partial \bar{u}}{\partial p} \approx \frac{1}{a \cos ^{2} \phi} \frac{\partial\left(\cos ^{2} \phi \overline{u^{\prime} v^{\prime}}\right)}{\partial \phi}+\frac{\partial \overline{u^{\prime} \omega^{\prime}}}{\partial p}$,

where $\overline{(\cdot)}$ indicates a zonal and monthly mean and $(\cdot)^{\prime}$ are deviations thereof and all variables have their usual meanings. Neglecting the vertical advection of angular momentum by the mean meridional circulation, the approximate free-tropospheric balance becomes

$$
(f+\bar{\zeta}) \bar{v}=f(1-\mathrm{Ro}) \bar{v} \approx \mathcal{S},
$$

with local Rossby number Ro $=-\bar{\zeta} / f$ and eddy momentum flux divergence $\mathcal{S}$ (Walker and Schneider 2006; Schneider 2006). Consider two limits of this three-term

\footnotetext{
${ }^{4}$ Formulas in the text are expressed in pressure coordinates, but the GCM simulations are analyzed in the model's $\sigma$ coordinate, with the appropriate surface pressure weighting of averages.
} 

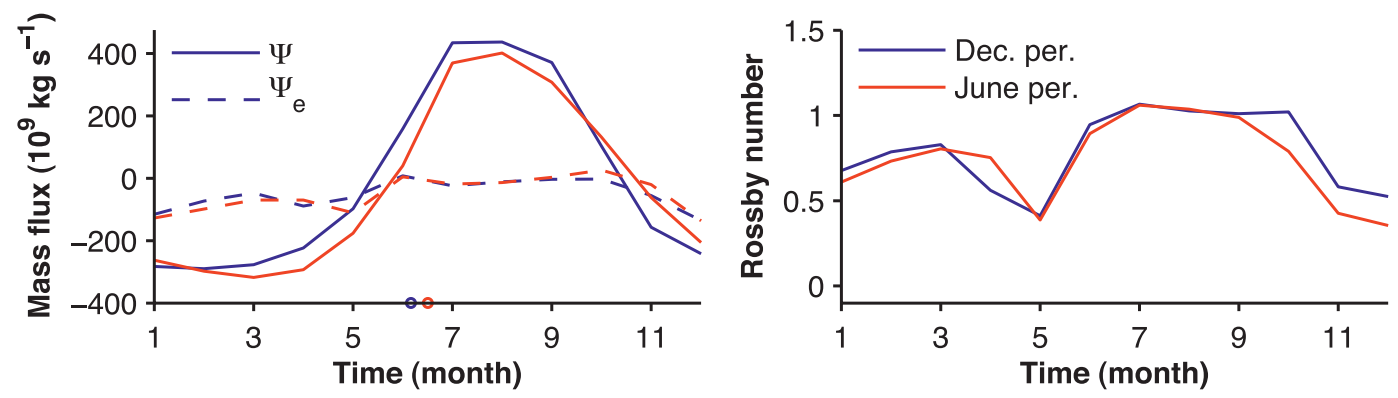

FIG. 7. (left) Seasonal cycle of the streamfunction (solid) and eddy component of the streamfunction (dashed) evaluated on the $\sigma=0.67$ model level at $\phi=15^{\circ} \mathrm{N}$ for simulations with perihelion in June (red) and December (blue). Markers on the horizontal axis indicate the time of year of the Northern Hemisphere summer solstice. (right) Seasonal cycle of the vertically averaged Rossby number $\langle$ Ro $\rangle$ above the $\sigma=0.67$ model level at $\phi=15^{\circ} \mathrm{N}$.

angular momentum balance: small and large Rossby number.

When the Rossby number is small (Ro $\sim 0$ ), the meridional circulation responds directly to eddy angular momentum flux divergences, $f \bar{v} \approx \mathcal{S}$, and the mean meridional circulation is slaved to the turbulent eddy stresses. This regime occurs over a wide range of simulated equinox Hadley circulations in dry atmospheres and in Earth's atmosphere during equinox and in the annual mean (Walker and Schneider 2006; Schneider et al. 2010; Levine and Schneider 2011). In this limit, a theory for the strength of the Hadley circulation depends on a closure theory for the magnitude of the eddy momentum flux divergence (Walker and Schneider 2006; Schneider and Walker 2008).

When the Rossby number is large (Ro $\sim 1)$, the mean meridional circulation is angular momentum-conserving, as $f(1-\mathrm{Ro})=-\left(a^{2} \cos \phi\right)^{-1} \partial_{\phi} \bar{M} \approx 0$, where $\bar{M}=$ $(\Omega a \cos \phi+\bar{u}) a \cos \phi$ is the absolute angular momentum per unit mass. In this limit of the angular momentum balance, the mean meridional velocity decouples from the momentum balance and the circulation is determined by energetic and radiative considerations (Held and Hou 1980; Held 2001a; Schneider 2006).

The mean meridional circulation can be decomposed into components that are associated with the divergence of eddy and mean-flow momentum fluxes (Seager et al. 2003; Schneider and Bordoni 2008; Levine and Schneider 2011). The eddy-driven component of the streamfunction is defined by the integral of the eddy momentum flux divergence from the top of the atmosphere to pressure $p$,

$$
\Psi_{e}(\phi, p)=-\frac{2 \pi a \cos \phi}{f g} \int_{0}^{p} \mathcal{S} d p^{\prime} .
$$

The mean-flow momentum flux component of the streamfunction is defined analogously,

$$
\Psi_{m}(\phi, p)=-\frac{2 \pi a \cos \phi}{f g} \int_{0}^{p} \mathcal{M} d p^{\prime}
$$

where $\mathcal{M}$ is the mean-flow momentum flux divergence including the vertical momentum advection. With these definitions, a vertically averaged local Rossby number can be defined as

$$
\langle\text { Ro }\rangle=\frac{\Psi_{m}}{\Psi}=\frac{\Psi_{m}}{\Psi_{m}+\Psi_{e}} .
$$

\section{b. Simulation results}

Figure 7 shows the seasonal cycle of the eddy component of the streamfunction and the total (sum of mean and eddy components) streamfunction (left panel) and the Rossby number (right panel) at $\phi=15^{\circ} \mathrm{N}$. Note that Figs. 4 and 5 show contours of the total streamfunction. The simulated seasonal cycle of the angular momentum balance and Rossby number resembles that of Earth (e.g., Bordoni and Schneider 2008; Schneider et al. 2010), but the low Rossby number equinox regime is present for a short period of time. Near the solstices, there is a strong, cross-equatorial winter Hadley cell that has large Rossby number and a weak summer Hadley cell that has small Rossby number (Fig. 5; however, note that the extremum of the summer cell is below the contour interval). The cross-equatorial circulation has a large amplitude in the Northern Hemisphere summer, while the eddy-driven streamfunction is weak $(<50 \times$ $10^{9} \mathrm{~kg} \mathrm{~s}^{-1}$ ) and of opposite sign (Fig. 7), which is consistent with the eddy angular momentum flux convergence near the equator (Fig. 5). The Rossby number at $15^{\circ} \mathrm{N}$ is close to one in this season, and so the strength of the mean meridional circulation is not directly determined by the angular momentum balance.

In Northern Hemisphere winter, the streamfunction at $\phi=15^{\circ} \mathrm{N}$ is strong and of opposite sign (i.e., it is the 
cross-equatorial winter cell, which ascends in the Southern Hemisphere), and the eddy-driven streamfunction is less than half of the total streamfunction (Fig. $5)$. The Rossby number is somewhat greater than 0.5 . In simulations with $20-\mathrm{m}$ slab depth, the descending branch of the winter Hadley circulation is closer to the eddydriven regime $(\mathrm{Ro} \sim 0.3)$, consistent with reanalysis estimates of Earth's Hadley cells (Schneider 2006). The subtropical eddy momentum fluxes contribute to the strength of the mean meridional circulation in the winter hemisphere subtropics (see, e.g., the Southern Hemisphere subtropics in Fig. 5) but not in the summer hemisphere. The implications of the seasonal cycle in the Rossby number on annual-mean circulation changes are discussed in Part II.

The seasonal cycle of the Rossby number does not change substantially when the perihelion is varied: In the summer hemisphere, the cross-equatorial Hadley cell is nearly angular momentum conserving. In the winter hemisphere, the cross-equatorial Hadley cell is influenced by eddies and the Rossby number is $\sim 0.5$ (Fig. 7).

The Hadley circulation mass flux is weaker when the perihelion is in June than when it is in December; that is, the Hadley circulation strength decreases as the insolation and insolation gradient increase. This seems to defy intuition based on the off-equatorial extension of the angular momentum-conserving Hadley circulation theory (Lindzen and Hou 1988), an issue that we return to in the next section. As this result may be unexpected, it is worth noting that the comprehensive atmospheric GCM-slab-ocean simulations presented in Clement et al. (2004) have similar changes in Hadley circulation strength in the lower troposphere when the perihelion is varied in a similar manner to the simulations presented here, albeit with smaller eccentricity (cf. their Figs. 5, 10, which show cross-equatorial Hadley circulations that are weaker by $\sim 10 \%$ when the insolation is stronger).

The simulated angular momentum balance can be summarized as follows: The momentum balance varies seasonally between one that approaches the angular momentum-conserving limit near the solstices and one that is influenced by extratropical eddies near the equinoxes (Fig. 7, right). The influence of extratropical eddies, as measured by the component of the Hadley circulation mass flux associated with their momentum flux divergence, does not change substantially with the phase of perihelion (dashed lines in Fig. 7, left). The total Hadley circulation mass flux (solid lines in Fig. 7, left) does change with the phase of perihelion. Therefore, the response of the Hadley circulation mass flux to orbital precession is largely associated with the precession-forced changes to the circulation's energy balance.

\section{Energy balance}

We focus on the energy balance to understand the mean atmospheric circulations because, in contrast to the dry thermodynamic budget or water vapor budget, it does not have a source term proportional to precipitation. When one attempts to apply the water vapor budget to understand mean circulation changes, details of the spatial structure of the precipitation change are necessary to obtain quantitatively accurate estimates (Merlis and Schneider 2011). However, the analysis of tropical circulation changes is motivated, in part, by the desire to understand regional precipitation changes (e.g., the annual-mean precipitation changes of these simulations; Merlis et al. 2013b). Therefore, we avoid interpreting the circulation changes using the dry thermodynamic budget or water vapor budget.

\section{a. Theory}

The time-dependent, vertically integrated (over the atmospheric column, denoted $\{\cdot\}$ ) energy balance of the atmosphere is

$$
\begin{aligned}
\left\{\frac{\partial \overline{\mathcal{E}}}{\partial t}\right\}= & -\nabla \cdot\{\overline{\mathbf{u} h}\}+S_{\mathrm{TOA}}-L_{\mathrm{TOA}} \\
& -S_{\text {surf }}+L_{\text {surf }}+\mathrm{LE}+H,
\end{aligned}
$$

with total atmospheric energy (neglecting kinetic energy) $\mathcal{E}=c_{v} T+g z+L q$, moist static energy $h$, net topof-atmosphere shortwave radiation $S_{\mathrm{TOA}}$, net top-ofatmosphere longwave radiation $L_{\mathrm{TOA}}$, net surface shortwave radiation $S_{\text {surf }}$, net surface longwave radiation $L_{\text {surf }}$, latent surface enthalpy flux LE, and sensible surface enthalpy flux $H$. Note that moist static energy $h$ is not a materially conserved quantity (e.g., Neelin 2007). The surface energy evolution is governed by

$$
\rho_{o} c_{p o} d \frac{\partial \bar{T}_{s}}{\partial t}=S_{\text {surf }}-L_{\text {surf }}-\mathrm{LE}-H-\nabla \cdot \mathbf{F}_{o}
$$

with water density $\rho_{o}$, water heat capacity $c_{p o}$, mixed layer depth $d$, surface temperature $T_{s}$, and ocean energy flux divergence $\boldsymbol{\nabla} \cdot \mathbf{F}_{o}$. Summing over the surface and atmosphere, this is a three-term equation with energy storage, energy flux divergence, and radiative imbalance terms

$$
\left\{\frac{\partial \overline{\mathcal{E}}}{\partial t}\right\}+\rho_{o} c_{p o} d \frac{\partial \bar{T}_{s}}{\partial t}=S_{\mathrm{TOA}}-L_{\mathrm{TOA}}-\nabla \cdot\{\overline{\mathbf{u} h}\}-\nabla \cdot \mathbf{F}_{o}
$$


When averaged for a sufficient time that the storage terms are small, the familiar result that the ocean and atmosphere energy flux divergences balance the top-ofatmosphere radiative imbalance is obtained: $S_{\mathrm{TOA}}-$ $L_{\mathrm{TOA}}=\boldsymbol{\nabla} \cdot\{\overline{\mathbf{u} h}\}+\boldsymbol{\nabla} \cdot \mathbf{F}_{o}$. Consider two limiting balances for the seasonal cycle: large and small energy storage. If the energy storage is large, the seasonally varying net radiation can be balanced by the energy storage without changes in the energy flux divergence. In this case, the atmospheric circulation does not respond directly to balance the radiation changes through changes in atmospheric energy flux divergence. The atmospheric circulation can be perturbed indirectly through changes in the thermal properties of the surface, which can change the circulation boundaries (Privé and Plumb 2007; Part II) or can change the partition between the circulation mass transport and energetic stratification (discussed next).

If the energy storage is minimal, there is a balance between the energy flux divergences and the top-ofatmosphere radiation, as in the annual mean. In this limit, assuming eddy moist static energy flux divergences are small, we have

$$
\partial_{y}(V \Delta h)+\nabla \cdot \mathbf{F}_{o}=S_{\mathrm{TOA}}-L_{\mathrm{TOA}},
$$

where the gross moist stability (GMS) $\Delta h$ is the difference between the typical moist static energy $h$ in the upper branch and lower branch of the Hadley cell $\Delta h=\bar{h}\left(p_{\text {up }}\right)-\bar{h}\left(p_{\text {low }}\right)$ and the meridional velocity $V$ is the typical velocity in the upper branch of the Hadley cell $^{5}$ (cf. Held 2001a). It is clear that the energy balance does not require a particular Hadley circulation strength; the energy balance constrains the product of the Hadley circulation mass flux and the GMS.

Kang et al. $(2008,2009)$ developed a theory for precipitation changes in response to changes in crossequatorial ocean energy fluxes based on the atmospheric energy balance by assuming that thermodynamic changes in the water vapor budget are negligible and that the control GMS can be used in perturbed climates (i.e.,

\footnotetext{
${ }^{5}$ The GMS is evaluated in the simulations using $\Delta h=\{\bar{v} \bar{h}\} / \Psi(\sigma=0.67)$. In the limit of the mean meridional circulation being confined to pressure levels $p_{\text {up }}$ and $p_{\text {low }}$, the formula reduces to that defined following (11). The definition used to evaluate the simulations accounts for the effect that the vertical structure of the mean meridional circulation has on the atmospheric energy flux, so that, when multiplied by the meridional velocity vertically integrated over the upper branch of the Hadley cell $\Psi\left(p_{\text {mid }}\right)$, it is equal to the vertically integrated moist static energy flux. There are other definitions of GMS in the literature (cf. Raymond et al. 2009).
}

GMS perturbations are negligible). ${ }^{6}$ In the simulations presented here, changes in GMS and in the thermodynamic component of the water vapor flux (the component associated with unchanged winds and perturbed specific humidities) are not negligible (Merlis et al. 2013b). In this section, we will examine the changes in the atmospheric energy fluxes and GMS to understand their role in determining the changes in the mean circulation.

The perturbation form of the approximate energy balance (11), neglecting quadratic perturbations and changes in the ocean energy flux divergence, is

$$
\partial_{y}(\delta V \Delta h)=\delta S_{\mathrm{TOA}}-\delta L_{\mathrm{TOA}}-\partial_{y}(V \delta \Delta h) .
$$

The perturbation energy budget shows that a change in top-of-atmosphere insolation gradient, such as a larger gradient in the summer season when the perihelion occurs near the summer solstice, can be balanced by (i) a larger gradient in the top-of-atmosphere longwave radiation (though this does not generally occur because of the weakness of the tropical temperature variations), (ii) an increase in the mean meridional mass flux, or (iii) an increase in the GMS.

A simple estimate of the GMS variations given the surface temperature and relative humidity is provided by arguments presented in Held (2001b): Assuming the moist static energy of the upper troposphere is approximately uniform (consistent with weak temperature gradients and low specific humidities), the GMS increases with latitude away from the ascending branch of the Hadley circulation as the surface enthalpy decreases. The resulting estimate for the GMS takes the form

$$
\left.\Delta h(\phi)\right|_{\mathrm{H} 01}=\bar{h}_{s}\left(\phi_{1}\right)-\bar{h}_{s}(\phi),
$$

where $\bar{h}_{s}$ is the near-surface time- and zonal-mean moist static energy and $\phi_{1}$ is the latitude of the ascending branch of the Hadley circulation. If this is an adequate description, the GMS of the Hadley circulation will be larger in the summer with greater insolation and insolation gradients because the meridional surface enthalpy gradient will be greater, as the increase in insolation will be balanced by surface fluxes that increase the surface temperature and specific humidity. A potential consequence is that, instead of the mean meridional mass flux strengthening to achieve increased energy flux across the equator to offset the larger cross-equatorial insolation gradient, the

\footnotetext{
${ }^{6}$ The definition of the GMS in Kang et al. (2009) includes transient eddy moist static energy fluxes in addition to the meanflow component considered here.
} 


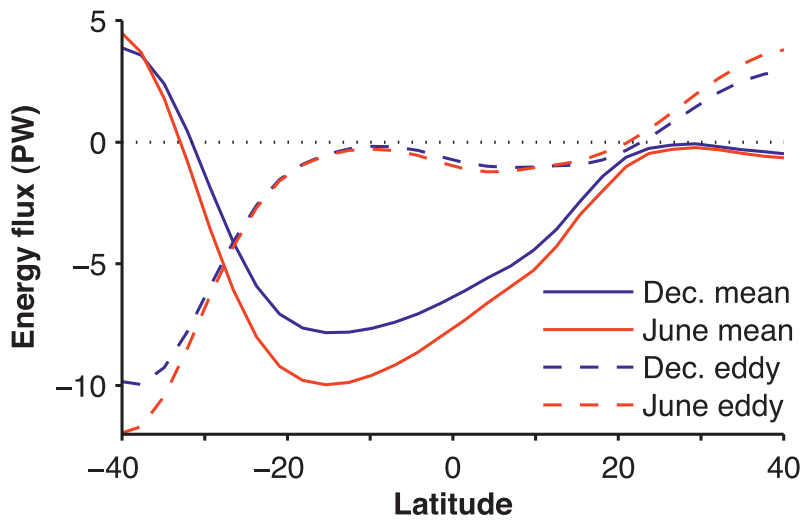

FIG. 8. JAS meridional energy flux of the mean flow (solid) and transient eddies (dashed) for simulations with December perihelion (blue) and June perihelion (red)

GMS increases so that the circulation changes little or even weakens.

To further consider the implications of energy balance on the mean meridional circulation, we consider the region near the streamfunction extremum, where $\partial_{y} V \approx 0$. The approximate perturbation energy budget in this region is

$$
\delta V \partial_{y} \Delta h=\delta\left(S_{\mathrm{TOA}}-L_{\mathrm{TOA}}\right)-V \partial_{y}(\delta \Delta h) .
$$

If the perturbation GMS $\delta \Delta h$ is decomposed into changes that vary in latitude $\delta \Delta h^{\prime}(\phi)$ and changes that do not depend on latitude $\delta\langle\Delta h\rangle$, we have

$\delta V \partial_{y} \Delta h=\delta\left(S_{\mathrm{TOA}}-L_{\mathrm{TOA}}\right)-V \partial_{y}\left(\delta \Delta h^{\prime}+\delta\langle\Delta h\rangle\right)$.

Fractional changes in the mean meridional circulation can be expressed as

$$
\frac{\delta V}{V}=\frac{\delta\left(S_{\mathrm{TOA}}-L_{\mathrm{TOA}}\right)}{S_{\mathrm{TOA}}-L_{\mathrm{TOA}}}-\frac{\partial_{y}\left(\delta \Delta h^{\prime}+\delta\langle\Delta h\rangle\right)}{\partial_{y}\left(\Delta h^{\prime}+\langle\Delta h\rangle\right)} .
$$

Individual terms on the right-hand side can be estimated as follows: For the latitude-dependent GMS $\Delta h^{\prime}$, we use Held's (2001b) estimate (13). For typical tropical conditions, changes in surface shortwave radiation are balanced by surface fluxes that act to change the surface moist static energy proportionately, $\delta \bar{h}_{s} \sim \delta S_{\text {surf }}$. In the absence of cloud changes, the surface shortwave radiation varies with the top-of-atmosphere shortwave radiation, $\delta S_{\text {surf }} \sim \delta S_{\text {TOA. }}$. Putting together these scaling estimates for perihelion insolation variations, which have spatial scales greater than that of the Hadley cell, the fractional changes in the latitude-dependent GMS scale with the top-of-atmosphere insolation changes, $\partial_{y}\left(\delta \Delta h^{\prime}\right) \sim \partial_{y} S_{\mathrm{TOA}} \sim \delta S_{\mathrm{TOA}}$, as variations in insolation and insolation gradients are similar because they arise from the altered Earth-Sun distance. In the absence of the latitude-independent GMS $\langle\Delta h\rangle$, this argument implies that the changes in GMS would balance the top-ofatmosphere radiation changes, and the mean meridional circulation would be unchanged (but, with nonzero latitude-independent GMS $\langle\Delta h\rangle$, the sign of the circulation changes may depend on $\delta\langle\Delta h\rangle$ ).

It is worth considering the implications of (16) for greenhouse gas-forced Hadley circulation changes. In the absence of spatially inhomogeneous climate feedbacks when the energy balance has reached a new equilibrium [i.e., $\delta\left(S_{\mathrm{TOA}}-L_{\mathrm{TOA}}\right)=0$ ], the mean circulation responds to changes in the GMS. Relative to precession variations, one might expect the temperature and humidity changes to have less spatial structure for greenhouse gas changes, so the latitude-independent GMS changes may be dominant in determining the circulation changes when it is near the angular momentumconserving limit, $\delta V \sim-\delta\langle\Delta h\rangle$. However, Sobel and Camargo (2011) analyzed the multimodel mean of the simulations carried out for the Intergovernmental Panel on Climate Change Fourth Assessment Report and found that the meridional gradients in summer-season surface temperature increase, which would lead to an increased latitude-dependent GMS according to the Held estimate and hence may account for some of the weakening of the cross-equatorial Hadley circulation found in those simulations. Additionally, the effect of spatially inhomogeneous climate feedbacks on the topof-atmosphere radiation balance cannot typically be neglected in global warming simulations (e.g., Frierson and Hwang 2012).

\section{b. Simulation results}

Figure 8 shows the mean-flow and transient eddy moist static energy flux in Northern Hemisphere summer. The mean-flow component of the moist static energy flux dominates the transient eddy energy flux in the deep tropics. The seasonal energy fluxes are larger than observed because of the low thermal inertia of the surface and therefore smaller energy storage. When the perihelion is in Northern Hemisphere summer, the southward, cross-equatorial mean-flow component of the energy flux increases by $\sim 20 \%$, while the eddy component is essentially unchanged. So, the energy fluxes associated with the mean meridional circulation balance the insolation changes. Next, we examine the GMS and its changes to understand how the mass and energy fluxes of the Hadley circulation are related.

The simulated GMS in the summer season changes with the phase of perihelion (Fig. 9). When perihelion occurs in June, the GMS of the Northern Hemisphere 


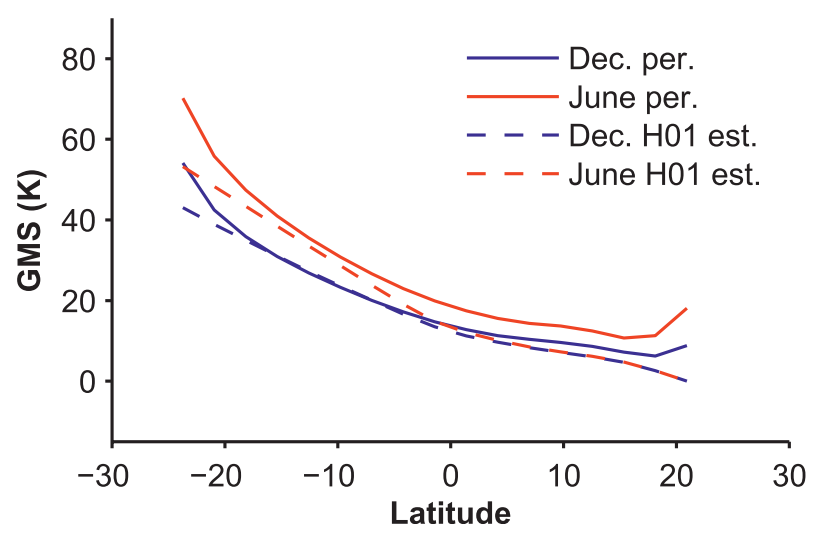

FIG. 9. Gross moist stability $\Delta h=\{\bar{v} \bar{h}\} / \Psi(\sigma=0.67)$ divided by $c_{p}$ to convert to units of kelvin for simulations with December perihelion (blue solid line) and June perihelion (red solid line) averaged over July, August, and September. Held (2001b) estimate for gross moist stability (13) using time-mean near-surface $(\sigma=0.96$ model level) moist static energy of simulation with December perihelion (blue dashed line) and June perihelion (red dashed line).

monsoonal Hadley cell is $\sim 30 \%$ larger than when it occurs in December. Figure 9 also assesses Held's GMS estimate (13) using the GCM-simulated surface moist static energy. This estimate captures the sign and magnitude of the changes in the Southern Hemisphere (south of $\sim 10^{\circ} \mathrm{S}$ ), though there are GMS changes in the region of ascent $\left(0^{\circ}-20^{\circ} \mathrm{N}\right)$ that are not captured. The discrepancy in the Northern Hemisphere is due, in part, to the assumption that the GMS is zero in the ascending branch of the circulation. If the GCM-simulated GMS in the ascending branch $(\langle\Delta h\rangle$ in the notation of section 5a) is added to the Held estimate, the precession-forced GMS changes in the GCM simulations and estimate have similar fractional variations over the range of latitudes that the cross-equatorial circulation spans, though the GMS estimate has larger mean values than the corresponding GCM simulation.

In the ascending region, the circulation shifts upward when the perihelion occurs in June (Fig. 5), which would lead to an increase in GMS in the absence of changes to the moist static energy distribution (see, e.g., Sobel 2007, Fig. 3). However, the vertical moist static energy distribution does change, and it is possible to have an upward shift of the circulation and an unchanged GMS, as approximately happens in global warming simulations performed with a similar GCM (Levine and Schneider 2011). Which factors determine the GMS in ascending regions is an outstanding question (see review by Raymond et al. 2009). However, the simulation results and considerations from the conceptual Held (2001b) model of the GMS clearly illustrate that the response of the cross-equatorial circulation to increased insolation gradients is not necessarily a strengthening of the mass transport of the circulation.

The simulated atmospheric energy balance can be summarized as follows: Increasing insolation gradients when the perihelion occurs in Northern Hemisphere summer are balanced by increased cross-equatorial atmospheric energy fluxes ( $\sim 20 \%$ larger). The increased nearsurface enthalpy gradient increases the GMS $(\sim 30 \%)$. Thus, the Hadley circulation mass flux is reduced $(\sim 10 \%)$.

In simulations with 20 -m slab depth, the JAS meanflow moist static energy flux changes little when perihelion is varied. Nevertheless, the JAS Hadley circulation mass flux is weaker in the June perihelion simulation than in the December perihelion simulation because the GMS increases. We have also obtained similar results in simulations with time-independent, nonequinox insolation: for example, insolation fixed at 30 days after Northern Hemisphere vernal equinox (Merlis 2012).

\section{Annual-mean circulation changes}

In this section, the mechanism that gives rise to the annual-mean Hadley circulation changes is considered. For there to be annual-mean changes in response to perihelion variations, which do not change the annualmean insolation, there must be a nonlinear process acting. The analysis of the circulation changes has thus far focused on the summer-season changes; however, these changes are useful for understanding the annual-mean changes.

A consequence of the precession-forced insolation changes having opposite sign in different seasons (Fig. 2) is that, in simulations with hemispherically symmetric boundary conditions, examining one solstice lends insight into changes in the other solstice. The combined change from the two solstice seasons affects the annual-mean Hadley circulation. This is because the changes in circulation near the December solstice will have the same sign as the changes near the June solstice (and thus add together to change the annual mean): the cross-equatorial JAS Hadley cell, which is positive in the climatology, weakens (negative perturbation streamfunction) when perihelion changes from the Southern Hemisphere summer solstice to the Northern Hemisphere summer solstice (making that season brighter), and the cross-equatorial JFM Hadley cell, which is negative in the climatology, strengthens (negative perturbation streamfunction) when perihelion is changed from the Southern Hemisphere summer solstice to the Northern Hemisphere summer solstice (making that season dimmer). Thus, the perturbation streamfunction in both solstice seasons has the same sign because the climatological streamfunction reverses sign.

In addition to providing a mechanism for annualmean Hadley circulation changes, the solstice-season 
cross-equatorial Hadley circulation changes approximately account for the magnitude of the simulated changes in the annual-mean streamfunction. The 3-month averages following the solstices have $\sim 50 \times 10^{9} \mathrm{~kg} \mathrm{~s}^{-1}$ negative streamfunction anomalies and the annual-mean streamfunction anomaly $\left(\sim 25 \times 10^{9} \mathrm{~kg} \mathrm{~s}^{-1}\right)$ is roughly half this magnitude (Figs. 5, 4).

In the simulations presented here, the nonlinear Hadley cell regime of the angular momentum-conserving limit gives rise to the changes in the annual-mean circulation when perihelion varies. The annual-mean circulation is stronger in the hemisphere with perihelion occurring at that hemisphere's summer solstice (Fig. 4). This is the result of the GMS increasing rapidly as the insolation increases; the increase in GMS is so rapid that the GMS changes are larger than that necessary to achieve the energy flux changes mandated by the top-of-atmosphere radiation changes. Held's estimate lends insight into why the GMS can increase rapidly: the GMS nonlocally maps the surface enthalpy gradient into a vertical stability, so the GMS at a given latitude depends not only on the local surface enthalpy but also on the surface enthalpy difference between that latitude and the latitude of the ascending branch of the circulation. In addition to the changes in GMS associated with the latitudinal moist static energy variations, the GMS increases in the ascending branch of the circulation.

\section{Conclusions}

Monsoonal Hadley circulations are near the angular momentum-conserving limit (Ro $\sim 1)$. Therefore, the circulation response to radiative perturbations is energetically constrained.

Interestingly, the solstitial Hadley cell can defy the expectation that the strength of the mean meridional circulation increases with increasing insolation gradients. This is at odds with the intuition that the circulation strength increases with insolation gradients, something that would be expected from both sea-breeze circulations and angular momentum-conserving Hadley circulations with fixed gross (moist) stability. This result can be understood by considering the atmospheric energy balance: insolation changes and the implied changes in atmospheric energy fluxes constrain the product of the mass flux and the relevant energy contrast of the mean circulation, the gross moist stability (GMS). The changes in GMS under precession variations are sufficiently large that the Hadley circulation mass fluxes are actually weaker in the solstice season that coincides with perihelion. While the simulations presented here have a small surface thermal inertia so that the storage terms are small and the atmospheric energy flux divergence changes to meet the top-of-atmosphere radiation changes, changes in the GMS are important in determining the strength of mean circulation mass transports even if the energy storage is large enough that the atmospheric energy flux divergence does not need to change. It is plausible that the different circulation responses to perihelion variations found in comprehensive GCM simulations (described in the introduction) are due to differences in model formulation, such as convection schemes, that lead to GCM-dependent sensitivities in GMS changes.

The annual-mean Hadley circulation changes are an average of the solstice-season changes. This is interesting in the sense that the annual-mean circulation is weak and low Rossby number, so one might expect that the changes in its strength are due to eddies. But, in fact, the annualmean Hadley circulation changes are the result of rectification of the changes that occur during times of year when the Hadley circulation is near the angular momentumconserving limit. Consistent with this mechanism, the Hadley circulation changes are largest near the equator where the Rossby number is higher. The rectification of the Hadley circulation and the role that the timedependent angular momentum balance plays is discussed more in Part II, where we also examine the effects of landsea contrasts in surface properties.

We have closely examined the effect of changing perihelion between solstice configurations, although the perihelion takes on intermediate values during the course of the precession cycle. The degree to which topof-atmosphere radiation changes directly affect tropical circulations depends on their Rossby number, so the magnitude and phasing of the circulation response to the full range of orbital configurations is potentially subtle. This is an important area for future study to aid in the interpretation of paleoclimate proxy records.

Acknowledgments. A careful reading of Tim Merlis's Ph.D. thesis by Andy Thompson is greatly appreciated. We thank Rob Korty and Damianos Mantsis for helpful comments on the manuscript. This work was supported by a National Science Foundation Graduate Research Fellowship, a Princeton Center for Theoretical Science Fellowship, and National Science Foundation Grant AGS-1049201. The program codes for the simulations, based on the Flexible Modeling System of the Geophysical Fluid Dynamics Laboratory, as well as the simulation results themselves, are available from the authors upon request.

\section{REFERENCES}

Anderson, J. L., and Coauthors, 2004: The new GFDL global atmosphere and land model AM2-LM2: Evaluation with prescribed SST simulations. J. Climate, 17, 4641-4673. 
Ashkenazy, Y., I. Eisenman, H. Gildor, and E. Tziperman, 2010: The effect of Milankovitch variations in insolation on equatorial seasonality. J. Climate, 23, 6133-6142.

Bordoni, S., 2007: On the role of eddies in monsoonal circulations: Observations and theory. Ph.D. dissertation, University of California, Los Angeles, 195 pp.

— transitions of the tropical overturning circulation. Nat. Geosci., 1, 515-519.

Braconnot, P., and Coauthors, 2007: Results of PMIP2 coupled simulations of the Mid-Holocene and Last Glacial MaximumPart 1: Experiments and large-scale features. Climate Past, 3, 261-277.

Brayshaw, D. J., B. Hoskins, and E. Black, 2010: Some physical drivers of changes in the winter storm tracks over the North Atlantic and Mediterranean during the Holocene. Philos. Trans. Roy. Soc. London, 368A, 5185-5223.

Clement, A. C., A. Hall, and A. J. Broccoli, 2004: The importance of precessional signals in the tropical climate. Climate Dyn., 22, 327-341.

Frierson, D. M. W., 2007: The dynamics of idealized convection schemes and their effect on the zonally averaged tropical circulation. J. Atmos. Sci., 64, 1959-1976.

_ , and Y.-T. Hwang, 2012: Extratropical influence on ITCZ shifts in slab ocean simulations of global warming. J. Climate, 25, 720-733.

Hartmann, D., 1994: Global Physical Climatology. Academic Press, $411 \mathrm{pp}$.

Held, I. M., 2001a: The general circulation of the atmosphere. Proc. 2000 Program in Geophysical Fluid Dynamics, Woods Hole Oceanographic Institution Tech. Rep. WHOI-2001-03, R. Salmon, Ed., Woods Hole Oceanographic Institution, 198 pp. [Available online at http://hdl.handle.net/1912/15.]

_ 2001b: The partitioning of the poleward energy transport between the tropical ocean and atmosphere. J. Atmos. Sci., 58, 943-948.

_ , and A. Y. Hou, 1980: Nonlinear axially symmetric circulations in a nearly inviscid atmosphere. J. Atmos. Sci., 37, 515-533.

Herweijer, C., R. Seager, M. Winton, and A. Clement, 2005: Why ocean heat transport warms the global mean climate. Tellus, 57A, 662-675.

Joussaume, S., and P. Braconnot, 1997: Sensitivity of paleoclimate simulation results to season definitions. J. Geophys. Res., 102 (D2), 1943-1956.

Kang, S. M., I. M. Held, D. M. W. Frierson, and M. Zhao, 2008: The response of the ITCZ to extratropical thermal forcing: Idealized slab-ocean experiments with a GCM. J. Climate, 21, 3521-3532.

- D. M. W. Frierson, and I. M. Held, 2009: The tropical response to extratropical thermal forcing in an idealized GCM: The importance of radiative feedbacks and convective parameterization. J. Atmos. Sci., 66, 2812-2827.

Khon, V. C., W. Park, M. Latif, I. I. Mokhov, and B. Schneider, 2010: Response of the hydrological cycle to orbital and greenhouse gas forcing. Geophys. Res. Lett., 37, L19705, doi:10.1029/2010GL044377.

Kutzbach, J., 1981: Monsoon climate of the early Holocene: Climate experiment with the Earth's orbital parameters for 9000 years ago. Science, 214, 59-61.

Levine, X. J., and T. Schneider, 2011: Response of the Hadley circulation to climate change in an aquaplanet GCM coupled to a simple representation of ocean heat transport. J. Atmos. Sci., 68, 769-783.

Li, J.-L. F., and Coauthors, 2008: Comparisons of satellites liquid water estimates to ECMWF and GMAO analyses, 20th century
IPCC AR4 climate simulations, and GCM simulations. Geophys. Res. Lett., 35, L19710, doi:10.1029/2008GL035427.

Lindzen, R. S., and A. Y. Hou, 1988: Hadley circulations for zonally averaged heating centered off the equator. J. Atmos. Sci., 45, 2416-2427.

Merlis, T. M., 2012: The general circulation of the tropical atmosphere and climate changes. Ph.D. dissertation, California Institute of Technology, $213 \mathrm{pp}$. [Available online at http:// resolver.caltech.edu/CaltechTHESIS:07012011-191902511.]

- and T. Schneider, 2010: Atmospheric dynamics of Earth-like tidally locked aquaplanets. J. Adv. Model. Earth Syst., 2, 13, doi:10.3894/JAMES.2010.2.13.

, and - 2011: Changes in zonal surface temperature gradients and Walker circulations in a wide range of climates. J. Climate, 24, 4757-4768.

,-- S. Bordoni, and I. Eisenman, 2013a: Hadley circulation response to orbital precession. Part II: Subtropical continent. J. Climate, 26, 754-771.

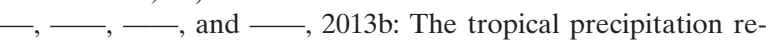
sponse to orbital precession. J. Climate, in press.

Neelin, J. D., 2007: Moist dynamics of tropical convection zones in monsoons, teleconnections, and global warming. The Global Circulation of the Atmosphere, T. Schneider and A. H. Sobel, Eds., Princeton University Press, 267-301.

O'Gorman, P. A., and T. Schneider, 2008: The hydrological cycle over a wide range of climates simulated with an idealized GCM. J. Climate, 21, 3815-3832.

Privé, N. C., and R. A. Plumb, 2007: Monsoon dynamics with interactive forcing. Part I: Axisymmetric studies. J. Atmos. Sci., 64, 1417-1430.

Raymond, D. J., S. Sessions, A. H. Sobel, and Z. Fuchs, 2009: The mechanics of gross moist stability. J. Adv. Model. Earth Syst., 1, 9, doi:10.3894/JAMES.2009.1.9.

Ruddiman, W. F., 2008: Earth's Climate: Past and Future. 2nd ed. W. H. Freeman and Company, 388 pp.

Schneider, T., 2006: The general circulation of the atmosphere. Annu. Rev. Earth Planet. Sci., 34, 655-688.

— , and S. Bordoni, 2008: Eddy-mediated regime transitions in the seasonal cycle of a Hadley circulation and implications for monsoon dynamics. J. Atmos. Sci., 65, 915-934.

_ , and C. C. Walker, 2008: Scaling laws and regime transitions of macroturbulence in dry atmospheres. J. Atmos. Sci., 65, 21532173.

- P. A. O'Gorman, and X. J. Levine, 2010: Water vapor and the dynamics of climate changes. Rev. Geophys., 48, RG3001, doi:10.1029/2009RG000302.

Seager, R., N. Harnik, Y. Kushnir, W. Robinson, and J. Miller, 2003: Mechanisms of hemispherically symmetric climate variability. J. Climate, 16, 2960-2978.

Sobel, A. H., 2007: Simple models of ensemble-averaged tropical precipitation and surface wind, given the sea surface temperature. The Global Circulation of the Atmosphere, T. Schneider and A. H. Sobel, Eds., Princeton University Press, 219-251.

, and S. J. Camargo, 2011: Projected future seasonal changes in tropical summer climate. J. Climate, 24, 473-487.

Walker, C. C., and T. Schneider, 2006: Eddy influences on Hadley circulations: Simulations with an idealized GCM. J. Atmos. Sci., 63, 3333-3350.

Webster, P. J., and J. Fasullo, 2003: Monsoon: Dynamical theory. Encyclopedia of Atmospheric Sciences, J. R. Holton, J. A. Curry, and J. A. Pyle, Eds., Academic Press, 13701386. 